\title{
BMJ Open Strategies used by emergency care professionals to handle interpersonal difficulties with patients: a qualitative study
}

Philippe Charrier (D) , 1,2 Pauline Occelli, ${ }^{2,3}$ Karine Buchet-Poyau, ${ }^{2}$ Marion Douplat, ${ }^{3,4}$ Marine Delaroche-Gaudin, ${ }^{5}$ Florence Fayard-Gonon, ${ }^{6}$ Laurent Jacquin, ${ }^{5}$ Véronique Potinet, ${ }^{4}$ Alain Sigal, ${ }^{6}$ Karim Tazarourte, ${ }^{3,5}$ Sandrine Touzet ${ }^{2,3}$

To cite: Charrier $P$, Occelli P, Buchet-Poyau K, et al. Strategies used by emergency care professionals to handle interpersonal difficulties with patients: a qualitative study. BMJ Open 2021;11:e042362. doi:10.1136/ bmjopen-2020-042362

- Prepublication history for this paper is available online. To view these files, please visit the journal online (http://dx.doi. org/10.1136/bmjopen-2020042362).

Received 20 July 2020 Revised 10 December 2020 Accepted 17 December 2020
Check for updates

(C) Author(s) (or their employer(s)) 2021. Re-use permitted under CC BY-NC. No commercial re-use. See rights and permissions. Published by BMJ.

For numbered affiliations see end of article.

Correspondence to

Sandrine Touzet;

sandrine.touzet@chu-lyon.fr

\section{ABSTRACT}

Objectives Identify the strategies implemented by emergency care professionals when facing tension and interpersonal violence from patients and their friends and family.

Design Descriptive qualitative study based on 38 semidirective interviews.

Participants Doctors, nurses, nursing assistants and administrative staff.

Setting Four emergency departments (EDs) from three French university hospitals.

Results According to the medical professionals interviewed, the difficulties that they encounter with patients or their accompanying family members can be explained by a lack of understanding of the functioning of EDs, by a general increase in individualistic behaviours leading to a lack of civility or by deviant behaviours (related to toxic substance abuse or mental illness). While managing deviant behaviours may sometimes require a collective intervention, ED staff also implement what are essentially individual communication strategies (with the use of rational explanation, seduction and empathy), confrontation or flight to deal with interpersonal difficulties. Conclusions Strategies used by staff members tend to be individualised for the most part, and some, such as confrontational or escape strategies, may not be adapted to all situations. In the face of difficulties between staff and patients, mediators, specialised in resolving conflict, could entrust some cases to professionals.

Trial registration number ClinicalTrials.gov Registry (NCT03139110).

\section{INTRODUCTION}

According to the 2019 report of the Observatoire National des Violences Hospitalières (French national observatory for hospital violence), acts of violence are on the rise, with attacks on people predominating over damage to property (theft, degradation). ${ }^{12}$ Many instances of violence are in fact acts of incivility, that is, a minor or 'mitigated' form, or 'symbolic violence, ${ }^{3}{ }^{4}$ which does not constitute an offence in itself. ${ }^{5}$
Strengths and limitations of this study

- This qualitative study of healthcare violence addressed all occupational categories in emergency departments.

- The interviews allowed an in-depth exploration of the experience of violence by healthcare professionals.

- The verbatim transcripts of in-depth interviews were analysed by a sociologist with experience in mediation and was recognised for his expertise in this field.

- Participants were staff from four emergency departments of three university hospitals in Lyon, France; hence, findings might be generalisable only to similar settings.

In emergency departments (EDs), this violence has been noted by several international studies. ${ }^{6-8}$ It affects all categories of staff, but nurses most of all. ${ }^{9-13}$ The large numbers of patients, their heterogeneity, the communication problems (due to language differences or other misunderstandings), the long wait times, and a lack of understanding of how patient triage and prioritising work can lead to conflict-filled situations between patients (and/or those accompanying them) and the medical staff. ${ }^{14-18}$

Acts of violence interfere with the functioning of ED (interrupted tasks), and the well-being of medical, allied and administrative staff in the workplace (stress, a feeling of being unappreciated, anger and even fear, dissatisfaction at work, burnout, an increase in team turnover rates). ${ }^{19-25}$ Violence perpetrated by patients and/or the people accompanying them occurs within a work environment that may already be difficult due to the flow of incoming patients, intense and irregular, night and day. ${ }^{186-28}$ 
Over the past decade, several studies have been conducted on strategies to combat violence at work in EDs. However, most of these studies have failed to identify effective interventions to reduce the occurrence of violent incidents. ${ }^{29}{ }^{30} \mathrm{~A}$ previous multicomponent programme conducted in an emergency unit has shown the potential interest of a mediator in response to situations of violence. ${ }^{31}$ Before setting up a mediation intervention, it is necessary to study the experiences about violence among the professionals who will be in contact with the mediators. Knowing these experiences makes it possible to adapt the mediation interventions to the difficulties and strategies already implemented by the professionals.

Our study aimed to identify the strategies that medical, allied and administrative staff tend to implement when confronted with such violence, or more generally with interpersonal difficulties with patients and/or those who accompany them. ${ }^{32-34}$

\section{METHODOLOGY}

\section{Research design and setting}

We conducted a descriptive qualitative study based on inductive approach. Semidirective interviews were conducted with staff from the four professional categories (doctors, nurses, nurse managers, administrative officers) present in the four EDs of three university hospitals in the Auvergne-Rhône-Alpes region (France). The mean number of admissions in these departments was 28000 patients per year.

\section{Participants}

The purposive sample was set up in accordance with the proportion of each category in relation to its distribution in terms of occupation, department and seniority within that department. Nurse managers were asked to inform the staff about the study (by email). About 50 staff members volunteered to participate. The practical terms of the interview (date, schedule and location) were determined on a case-by-case basis. Consent was required after participants were informed of the purpose of the study. Thirty-eight staff members were interviewed: 6 administrative officers ( 6 women), 13 nurses (10 women, 3 men) and 3 nurse managers ( 3 men), 9 nursing assistants ( 7 women, 2 men), and 7 doctors ( 5 men, 2 women). The average age was 42 years (minimum: 25; maximum: 59).

\section{Semidirective interviews}

Two interviewers shared this task equally: two male students enrolled in a master degree in social sciencesand trained in semidirective interviews. They were unrelated to the ED teams prior to the study. These interviews took place on the premises of the EDs during working hours, in the absence of any third party. The interview guide included two themes related to the experiences of the medical professionals: the types and nature of their relationships with patients and their accompanying family members, and the strategies or means used for dealing with difficult, contentious and/or violent situations. Duration ranged from $30 \mathrm{~min}$ to just over an hour. The interviews took place from 28 November 2017 to 26 January 2018. The interviews were fully recorded and transcribed. Transcripts were not returned to the participants. Participants were not asked to provide feedback on the results.

\section{Data analysis}

First, we carried out an analysis of the content of the transcribed interviews, which included a phase of coding and a phase of categorisation of the answers, and then the detectable links between these categories were analysed. A second level of analysis was carried out following three axes: (1) convergences/divergences in the way interpersonal problems are defined in EDs, (2) the subjective assessment of interpersonal difficulties with patients/ those accompanying them and (3) personal resources/ collective resources used to deal with conflict situations. All interviews were analysed, regardless of data saturation. Analyses were conducted by a sociologist $(\mathrm{PhD})$ with experience in mediation.

\section{Patient and public involvement}

Patients and the public were not involved in this research.

\section{RESULTS}

\section{Origins of interpersonal difficulties with patients}

Staff members described separate categories for conflicts, either stemming from a misunderstanding of the organisation of EDs, emanating from the behaviour of patients labelled as deviant, or explained by societal changes deemed regrettable (incivility).

\section{Patients' lack of understanding of how EDs function}

Some types of relationship-building practices on the part of medical staff are not feasible because of the intensity of their work. However, these practices involve transmitting information that concerns not only the patient but also the environment in which the patient is located. Staff members are put in a difficult position: they try to inform patients and field their questions, but they may not have all the answers.

Sometimes it's also difficult because they want their turn to come right away, it's complicated to handle, we try our best to explain how the department works, the specific functioning of the emergency department, but it's not always easy. (Female administrative officer)

These explanations help to alleviate potential tensions, based on the idea that a patient informed about the way an $\mathrm{ED}$ is run is a patient who will be better able to accept this functioning, along with the constraints and waiting time that go with it. When this explanation is not provided, the patient's behaviour may become violent.

It's more often people who get upset because they're tired of waiting or because 'I don't want to go back 
to Building X again', where you can bring in patients for particular types of hand injuries. We emergency doctors don't actually do much; it's the surgeons, except in an emergency department you have to wait for the surgeon to be available, to finish an operation, to come and see you; people will sometimes wait four, five, sixhour for someone to tell them, 'Well, there's no room today so you can come back tomorrow, we'll admit you tomorrow'. And things heat up and they get angry. (Male doctor)

Even when an effort is made to inform patients, this still does not mean that they have a full understanding of how the department functions. Staff do not have the time to properly manage these misunderstandings, which can be the sources of many conflicts and acts of violence.

\section{Deviant behaviour}

Deviant behaviour from people with identifiable social and/or medical characteristics (alcoholism, psychiatric illness, drug use) is less complicated to deal with because communication is already impaired due to the condition of the patient. ${ }^{35}{ }^{36}$ These types of patients do not try to make staff members enter into a relationship with them, they may even actively avoid such contact. Several protection strategies are available: limited contact, the presence of other trained professionals for this type of patient (psychiatric nurses) or restraint if the patient is agitated.

Often, when that happens, it is either because of purely psychiatric pathologies or what are called psychopaths in the medical field, that is, people who are not labelled with psychiatric conditions but who are very unstable in terms of their emotions and personalities, and with them it takes practically nothing for the situation to turn explosive (...). (Male doctor)

It might be expected that handling such patients would be especially difficult. However, situations like these often elicit a collective reaction that contrasts with the usual work of informing patients, in which cases the staff member is often alone in managing the situation. In the following account, we may note the presence of a hospital porter, security guards and a nurse.

A patient showed up in the emergency department, visibly drunk. I started hearing some aggravated tones at the reception desk. I was already nearby so I headed over there. He was in an argument with a porter at the time, insulting him. So he started to get angry, the porter started to get angry, but hey, he hadn't started it. The guards were already there, he had already insulted everyone in the reception area, and suddenly I arrived, I started talking to him, he started to say to me, 'Shut up, don't talk to me, who are you anyway? I'm going to bust your legs.' So I told him that he was going to have to listen to me and then I reminded him that in order for us to take care of him, he'd have to calm down, that he couldn't talk like that to the caregivers. (...) He started [verbally] attacking me and saying, 'If that's how it is I'm getting out of here, I'm going to leave anyway.' He insulted the security guards twice more and eventually calmed down. I told him that if the care we were trying to provide did not suit him, if he didn't like it, he could actually leave, and he left, he went out, I didn't hold him back. (Male nurse)

These deviant behaviours are not the most disturbing to deal with because staff are rarely isolated in these situations. They have resources available to help manage them. The responsibility in such situations shifts from individual to collective. In addition, communicating with an alcoholic patient or one under the influence of drugs is no simple matter, the staff member cannot be held responsible for deteriorating the relationships in such a case.

\section{Incivility, individualism, selfishness}

According to staff members, some behaviours that are considered as problematic might reflect an unfortunate change in the attitudes of individuals in social contexts, namely a lack of civic values and of courtesy. This is why the most frequent theme brought up by the health professionals during the interviews was incivility.

(...) Then again, I don't know, I don't have a problem with people - the only issue that comes up is rudeness. (...) Sometimes there are people whom I find poorly behaved, perhaps (...). (Female nurse)

According to the staff members, these incivilities can be explained by a wider trend-which they attribute to the modern society-of increasingly individualistic or selfish behaviour. They did not associate these acts with the suffering or anxiety of the patients or of those accompanying them. The staff considered that patients and/or their friends and family were at fault, lacking the basic manners needed for interacting with others, which explains why some suggested that a nationwide educational campaign should be carried out:

Or maybe it's a problem with people's upbringing from an early age, we need to re-educate the French population rather than adapt to the French population. Perhaps we should get them to understand that, actually, — no, that's a whole other debate but, well... (Female nurse)

Rudeness was also perceived in solicitations that were deemed inappropriate or repetitive. While not violent in the strict sense of the word, these solicitations have an impact on the work of hospital staff.

Because, well, these are not necessarily conflict situations but for example when patients keep showing up at the reception desk every five min to pester us, to say, 'Yes, I would like to get some news about so-andso, what's going on, why isn't anything happening?' It's not really aggressiveness or anything, it's more disruptive, but in these cases it's simply a question of manners, you know? (Female administrative officer) 
This type of judgement against patients was the most pronounced among those professionals who are the furthest removed from the work of providing medical care for patients in the ED, such as administrative officers, who can only build relationships with them based on administrative issues, and also among doctors.

\section{Strategies for handling interpersonal difficulties and violence}

The staff members expressed that they have a harder time knowing how to deal with cases of aggressive, individualised relationships involving minor violent behaviours (rudeness, verbal violence, insults and others) compared with violent physical conflicts (beatings, death threats, armed violence and others). Thus, they develop and adopt strategies that they present as personal, even if they may be similar from one professional to another, namely avoidance, a style of communication aimed at gaining a reciprocal understanding of the situation or confrontation.

\section{Avoidance and escape strategies}

These are ways for hospital employees to escape from a situation that is getting out of hand, when they feel that a patient is exerting a form of domination through violent behaviours or threats.

And sometimes, I have to admit, we escape precisely because we don't have the right techniques, I think. (Female nursing assistant)

Another nursing assistant cited avoidance as a way to keep from coming into overly direct contact with patients.

Sometimes we dodge a certain corridor so we won't have to come across the same people again, and have to listen to: 'Are things moving forward? What's going on?' 'Well, I already explained it to you, sir.' 'I'd like to see the doctor', and sometimes it drains you (...) And that's the main area where there can be conflicts. (Male nursing assistant)

Staff members admitted to experiencing such situations during the interviews but using this strategy was considered as akin to a failure in their relationship with the patient or with the person(s) accompanying the patient, even if doing so protects the hospital agent.

\section{Communication strategies}

This strategy brings together behaviours aimed at communicating effectively with patients and/or those accompanying them, that is, bringing about a reciprocal understanding of the situation. It involves an appeal to reason, along with rational explanations, seduction and empathy.

How do I go about it? Well, I let them talk. When they're done saying whatever is on their minds, I try to give them answers by telling them how things work here, why they're waiting, what's going on. And if they don't understand, well, what can I say? I keep letting them talk and then at some point they stop and then sometimes they leave by slamming the door. So I try to let them speak so that they can let it all out, and then after a while they calm down, once they've got it off their chests. (Female nurse)

In the above example, it sounds as if providing an explanation leads the patient to a fuller understanding (and therefore a better acceptance) of his/her situation, provided, however, that the situation itself also enters into rational logic. However, this is not always the case, as confirmed by this nurse.

Well, sometimes they go along with it, sometimes they don't. Sometimes they scream even more loudly. In the end it's... (sigh). We try to explain but at some point it doesn't work all the time. (Female nurse)

Medical professionals also use seduction techniques to keep the interaction pleasant and to avoid clashes. The goal is to involve the patient in the cause of the caregiver.

So I always try smiling, charming them first of all. Well, if it doesn't work, I can toughen up, but often it works very, very well. See, when you start to smile, the other person actually smiles as well... (Female nurse)

In general, smiling and trying to keep the interaction congenial can help these employees place the relationship under good auspices. This voluntary attitude does not merely reflect a sensitive intention. It also has a very pragmatic aim: to foster a peaceful and easy relationship.

I do a lot of moderating all the time, and I do it with a smile. And it's true that it calms things down, when someone shows up - I often deal with aggressive people, and, well, when I - with a smile: 'I'll look after you, sir, explain the problem to me, let's calm down', and it's true that it cools things down right away, when we take the tension out of the situation, actually. (Female administrative staff)

Finally, some medical professionals choose to develop an empathetic relationship.

So a lot, a lot of empathy. It does tend to bring them back from the edge when they feel that we're really putting ourselves in their shoes and that we understand what they are going through. So I think listening, empathy, is paramount in a situation of conflict... (Male nurse)

Other staff members made statements that were full of empathy, though less explicitly so, about the situations faced by patients, particularly about the issue of long wait times. For example, a nurse referred to her own experience involving queues at a large supermarket to explain how she was able to understand what a patient was going through.

\section{Confrontation strategies}

Another strategy involves the confrontation and the use of forms of aggression by the staff member, in response 
to the aggressiveness he or she perceives from patients or their accompanying family members. The staff member then uses personal resources that tend to establish the contentious nature of the interaction all the more firmly, therefore setting up a vertical relationship, or even one of domination, with the patient.

So I'm not that good at it! (laughs) I get carried away pretty quickly. (...) Honestly, I can't just let it go when I am verbally assaulted. I have a hard time keeping my cool. I tend to raise my voice, I remain polite, but I do raise my voice. (Female nurse)

'Raising one's voice' can be a double-edged sword. It may make the situation worse or it may effectively put an end to the aggression. Staff members who use this strategy do so individually but also collectively, especially during heated arguments. Finally, this strategy can also be concretised by calling for security guards, who represent the use of physical force, even if they do not implement it very often.

Since we, I mean the two people at the reception desk, are on the front line, and since the doctors are often behind us back there in the office, they hear what's going on, there is always someone who overhears, someone who warns the security department and then they come, they intervene. (Female administrative staff)

\section{DISCUSSION}

According to staff members, patients' factors that are associated with violence are a misunderstanding of the organisation of EDs, a societal incivility and deviant behaviours. Strategies implemented by hospital staff in the face of violence and, more generally, of interpersonal difficulties are multiple. ${ }^{35}$ They may involve communication strategies (with the use of rational explanation, seduction and empathy) and confrontational or flight-related behaviours. While the management of deviant behaviours can involve collective intervention, the strategies used to deal with difficult interactions are essentially individual.

Medical personnel acknowledge that their own behaviours may involve violent behaviours, such as confrontation, all the while disqualifying such violence. They do not recognise their own behaviour as potentially provoking subsequent violent interactions. Moreover, staff members describe certain patient behaviours as rude without considering their connection with the patient's illness, or with fear and anxiety on the part of the patient or his/her friends and family.

Our study confirms previous findings on staff members' perceptions of factors of violence in EDs. ${ }^{37}$ Indeed, literature reviews of qualitative studies of ED staff experiences of violence report a similar observation of: few staff members acknowledging their role in precipitating violence, ${ }^{37} 38$ workplace violence that can reduce the staff ability to feel compassion for the patients' illness, ${ }^{37} 3940$ staff members managing challenging situations of violence in isolation $^{38}$ and of violence judged depending on the patient's capacity to control their behaviour. ${ }^{38}$ The societal aspect of violence as perceived by staff members is also reported in previous studies. ${ }^{37}$

Strategies used by staff members are rarely the fruit of discussion and sharing. However, they admit to having a difficult time when it comes to responding individually, especially to the incivility of patients who do not have a markedly deviant character. The only collective strategies the study identified are those used to manage violence from deviant patients. Staff members seem more at ease when they have to manage this type of patient, despite the potential danger, because they are in a position of superiority through numbers. In addition, they are interacting with a disqualified subject. ${ }^{41}$

Studies describing strategies used by the medical personnel when dealing with interpersonal difficulties or violence from patients are rare. For emergency physicians, these strategies are more a matter of distancing themselves, ${ }^{42}$ which is seen as a defence mechanism. ${ }^{43}$ Concerning nurses, their strategies are more diverse and primarily involve finding someone to listen to and support patients, making sense of the situation involving violence, or relying on self-confidence and self-esteem. ${ }^{44}$ The strategy of escape or flight has barely been dealt with in the existing literature so far. ${ }^{35}$

There are sociological mechanisms at work behind these strategies. The caregiver-patient relationship in the ED has changed significantly and there is 'a growing intolerance among patients regarding the status of being hospitalised, and the dependence and even submission that this status implies'. ${ }^{45}$ The relationship between a caregiver and a patient cannot be taken for granted; it is a social construct that may be all the more difficult to establish because it takes time, which is exactly what ED personnel do not always have. However, we already know that when the individual being treated is 'dislodged from his position as a subject and becomes nothing more than the object of care' without any implicit agreement, tension and violence may arise. ${ }^{45}$

Support solutions for ED nurses currently include protection against such violence (emergency call buttons, video surveillance) and conflict-management training. ${ }^{13}$ These solutions will remain limited in their scope if we do not take note of the strategies that are already being implemented by hospital employees. ${ }^{34}$ As part of a policy aimed at better handling these situations involving violence, we need to identify those strategies that promote a positive relationship with patients so that the proposed solutions can strengthen or complement them.

The present study was conducted in emergency services from three university centres that are urban and with a high volume of admissions, which therefore limits the generalisability of our results to other settings. However, as the interviews allowed in-depth exploration of the topic, the transferability of findings might be possible to EDs of university hospitals in France with similar population 
health profiles. The use of purposive sampling ensured a wide variety of views, and experiences were accessed for analysis. Data saturation was not used to guide the recruitment of the interviewees; it might thus be possible that some dimensions of the topic were not identified.

Faced with the realisation that medical professionals sometimes demonstrate unsuitable demeanours towards their patients, the question arises of offering training that would target attitudes relating to de-escalation techniques, including non-confrontational language, active listening and attention to non-verbal cues and body language. ${ }^{34} 46$ However, according to a recent review, there is currently limited evidence that such training has an effect on de-escalation of aggressive behaviour. De-escalation is a highly specialised intervention and this might explain the limited effectiveness of the training programmes. ${ }^{47}$

We propose to entrust some cases involving difficult interactions to professional conflict resolution like mediators. They could intervene either to support hospital staff members or be fully and specifically invested in conflict resolution. These mediators could also work with professionals in spaces where they could discuss and share with one another the strategies they have developed to deal with interpersonal difficulties involving patients. To our knowledge, this strategy to reduce violence has not been mentioned in previous studies.

\section{REPORTING CRITERIA}

We followed the Consolidated criteria for Reporting Qualitative research from the Enhancing the QUAlity and Transparency Of Health Research network to report the study.

\section{Author affiliations \\ ${ }^{1}$ Centre Max Weber (UMR 5283), University Lumière Lyon 2, F-69007 Lyon, France \\ ${ }^{2}$ Public Health Department, Hospices Civils de Lyon, F-69003 Lyon, France \\ ${ }^{3}$ Health Services and Performance Research Lab (HESPER EA 7425), University \\ Claude Bernard Lyon 1, F-69008 Lyon, France \\ ${ }^{4}$ Emergency Department, Centre Hospitalier Lyon Sud, F-69310 Pierre-Bénite, France \\ ${ }^{5}$ Emergency Department, Edouard Herriot Hospital, F-69008 Lyon, France \\ ${ }^{6}$ Emergency Departement, Croix-Rousse Hospital, F-69004 Lyon, France}

Acknowledgements The authors acknowledge the help of head nurses in recruiting professionals: Alexandre Carabal, François Caremelle, Sonia CazabanMermillod, Sylvain Delome, Stephanie Desmarchelier and Yves-Marie Triboulet.The thank Sarah Novak, scientific translator.

Contributors The study was conceptualised and designed by PC, ST, KT and PO. ST, KB-P and KT served as scientific advisors. PC, sociologist, carried out the analyses of the interviews. MD-G, MD, FF-G, LJ, VP and AS participated in the discussion of the results led by the sociologist and the scientific advisors. PC, PO and ST drafted the manuscript. All authors reviewed the draft version, made suggestions and approved the final version.

Funding This study was supported by a grant from the programme de recherche sur la performance du système des soins (PREPS 2016) of the French Ministry of Health (Ministère chargé de la Santé, Direction de l'Hospitalisation et de l'Organisation des Soins).

\section{Competing interests None declared.}

Patient and public involvement Patients and/or the public were involved in the design, or conduct, or reporting, or dissemination plans of this research. Refer to the Methods section for further details.

\section{Patient consent for publication Not required.}

Ethics approval The trial was approved by the Institutional Review Board 17/48a (Sud-Est IV Ethical Research Committee) in September 2017. Under French law in effect at the time of the study, consent was not required for the type of study.

Provenance and peer review Not commissioned; externally peer reviewed.

Data availability statement Data are available upon reasonable request. The data (de-identified participant data) that support the findings of this study are available from the corresponding author, ST, upon reasonable request. However, according to the French law, data may not be analysed for purposes other than those for which the Institutional Review Board has given its approval.

Open access This is an open access article distributed in accordance with the Creative Commons Attribution Non Commercial (CC BY-NC 4.0) license, which permits others to distribute, remix, adapt, build upon this work non-commercially, and license their derivative works on different terms, provided the original work is properly cited, appropriate credit is given, any changes made indicated, and the use is non-commercial. See: http://creativecommons.org/licenses/by-nc/4.0/.

ORCID iD

Philippe Charrier http://orcid.org/0000-0003-0285-5216

\section{REFERENCES}

1 Liu J, Gan Y, Jiang H, et al. Prevalence of workplace violence against healthcare workers: a systematic review and meta-analysis. Occup Environ Med 2019;76:927-37.

2 Terrenoir V, Barat C. Rapport annuel de l'Observatoire national des violences en milieu de santé. Paris: Direction Générale de l'Offre de Soins, 2019.

3 Roché S. La société incivile : qu'est-ce que l'insécurité ? Droit et Société 1996;34:724-5.

4 Roché S. Tolérance zéro ?: incivilités et insécurité. Paris: Odile Jacob, 2002: 303.

5 Kopp N. Incivilités subies par les acteurs de santé l'hôpital. Aspects éthiques et sociétaux. Ethique Sante 2013;10:149-54.

6 Gerberich SG, Church TR, McGovern PM, et al. An epidemiological study of the magnitude and consequences of work related violence: the Minnesota nurses' study. Occup Environ Med 2004;61:495-503.

$7 \mathrm{NIOSH}$. Violence. occupational hazards in hospitals. Cincinnati, $\mathrm{OH}$ : Department of Health and Human Services, Public Health Service, Centers for Disease Control and Prevention, 2002: 101.

8 Winstanley S, Whittington R. Aggression towards health care staff in a UK General Hospital: variation among professions and departments. J Clin Nurs 2004;13:3-10.

9 Gates DM, Ross CS, McQueen L. Violence against emergency department workers. J Emerg Med 2006;31:331-7.

10 Lyneham J. Violence in New South Wales emergency departments. Aust J Adv Nurs 2000;18:8-17.

11 Pich J, Hazelton M, Sundin D, et al. Patient-Related violence at triage: a qualitative descriptive study. Int Emerg Nurs 2011;19:12-19.

12 Crilly J, Chaboyer W, Creedy D. Violence towards emergency department nurses by patients. Accid Emerg Nurs 2004;12:67-73.

13 Levin PF, Hewitt JB, Misner ST. Insights of nurses about assault in hospital-based emergency departments. Image J Nurs Sch 1998;30:249-54.

14 Ekwall A. Acuity and anxiety from the patient's perspective in the emergency department. J Emerg Nurs 2013;39:534-8.

15 Taylor DM, Wolfe R, Cameron PA. Complaints from emergency department patients largely result from treatment and communication problems. Emerg Med 2002;14:43-9.

16 Sun BC, Adams J, Orav EJ, et al. Determinants of patient satisfaction and willingness to return with emergency care. Ann Emerg Med 2000;35:426-34.

17 Taylor JL, Rew L. A systematic review of the literature: workplace violence in the emergency department. J Clin Nurs 2011;20:1072-85.

18 Davey K, Ravishankar V, Mehta N, et al. A qualitative study of workplace violence among healthcare providers in emergency departments in India. Int J Emerg Med 2020;13:33

19 Ngongo BT, Carlier A, Mols P. [Patient complaints in a hospital emergency department in Belgium]. Rev Med Liege 2011;66:199-204.

20 Fernandes CM, Bouthillette F, Raboud JM, et al. Violence in the emergency department: a survey of health care workers. CMAJ 1999;161:1245-8.

21 Almvik R, Woods P. Short-Term risk prediction: the Brøset violence checklist. J Psychiatr Ment Health Nurs 2003;10:236-8. 
22 Flannery RB. Violence in the workplace, 1970-1995: a review of the literature. Aggress Violent Behav 1996;1:57-68.

23 Dorevitch S, Forst L. The occupational hazards of emergency physicians. Am J Emerg Med 2000;18:300-11.

24 McGovern P, Kochevar L, Lohman W, et al. The cost of work-related physical assaults in Minnesota. Health Serv Res 2000;35:663-86.

25 Hislop E, Melby V. The lived experience of violence in accident and emergency. Accid Emerg Nurs 2003;11:5-11.

26 Stiell A, Forster AJ, Stiell IG, et al. Prevalence of information gaps in the emergency department and the effect on patient outcomes. CMAJ 2003;169:1023-8.

27 Horwitz LI, Green J, Bradley EH. Us emergency department performance on wait time and length of visit. Ann Emerg Med 2010;55:133-41.

28 Chisholm CD, Collison EK, Nelson DR, et al. Emergency department workplace interruptions: are emergency physicians "interrupt-driven" and "multitasking"? Acad Emerg Med 2000;7:1239-43.

29 Ramacciati N, Ceccagnoli A, Addey B, et al. Interventions to reduce the risk of violence toward emergency department staff: current approaches. Open Access Emerg Med 2016;8:17-27.

30 Spelten E, Thomas B, O'Meara PF, et al. Organisational interventions for preventing and minimising aggression directed towards healthcare workers by patients and patient advocates. Cochrane Database Syst Rev 2020;4:CD012662.

31 Touzet S, Occelli P, Denis A, et al. Impact of a comprehensive prevention programme aimed at reducing incivility and verbal violence against healthcare workers in a French ophthalmic emergency department: an interrupted time-series study. BMJ Open 2019;9:e031054.

32 Wolf LA, Delao AM, Perhats C. Nothing changes, nobody cares: understanding the experience of emergency nurses physically or verbally assaulted while providing care. J Emerg Nurs 2014:40:305-10.

33 Ramacciati N, Ceccagnoli A, Addey B. Violence against nurses in the triage area: an Italian qualitative study. Int Emerg Nurs 2015;23:274-80.

34 Wong AH-W, Combellick J, Wispelwey BA, et al. The patient care paradox: an interprofessional qualitative study of agitated patient care in the emergency department. Acad Emerg Med 2017;24:226-35.
35 Dadashzadeh A, Rahmani A, Hassankhani H, et al. Iranian pre-hospital emergency care nurses' strategies to manage workplace violence: a descriptive qualitative study. J Nurs Manag 2019;27:1190-9.

36 Hogarth KM, Beattie J, Morphet J. Nurses' attitudes towards the reporting of violence in the emergency department. Australas Emerg Nurs J 2016;19:75-81.

37 Ramacciati N, Ceccagnoli A, Addey B, et al. Violence towards emergency nurses. The Italian national survey 2016: a qualitative study. Int J Nurs Stud 2018;81:21-9.

38 Ashton RA, Morris L, Smith I. A qualitative meta-synthesis of emergency department staff experiences of violence and aggression. Int Emerg Nurs 2018;39:13-19.

39 Al-Qadi MM. Nurses' perspectives of violence in emergency departments: a metasynthesis. Int Emerg Nurs 2020;52:100905.

40 Vrablik MC, Chipman AK, Rosenman ED, et al. Identification of processes that mediate the impact of workplace violence on emergency department healthcare workers in the USA: results from a qualitative study. BMJ Open 2019;9:e031781.

41 Sainsaulieu I. Le bon patient est sous contrôle. Communautés de service et pratiques soignantes l'hôpital. Revue suisse de sociologie 2009;35:551-70.

42 Laurent A, Chahraoui K, Carli P. Les répercussions psychologiques des interventions médicales urgentes sur Le personnel SAMU. Étude Portant sur 50 intervenants SAMU. Ann Med Psychol 2007:165:570-8

43 McManus IC, Winder BC, Gordon D. The causal links between stress and burnout in a longitudinal study of UK doctors. Lancet 2002;359:2089-90.

44 Winiger $\mathrm{G}$. Les besoins et les stratégies des infirmières face la violence des patients en psychiatrie et aux urgences : une revue de littérature étoffée. Fribourg: Haute Ecole de Santé, 2011.

45 Monceau M. A propos de la régulation l'hôpital ou des modes d'évitement des situations potentiellement violentes. In: Pidolle A, ed. Droit d'être soigné, droit de soignants. Toulouse: Eres, 2003: 121-6.

46 Krull W, Gusenius TM, Germain D, et al. Staff perception of interprofessional simulation for verbal De-escalation and restraint application to mitigate violent patient behaviors in the emergency department. J Emerg Nurs 2019;45:24-30.

47 Raveel A, Schoenmakers B. Interventions to prevent aggression against doctors: a systematic review. BMJ Open 2019;9:e028465. 